\title{
Nas narrativas que atravessam as paisagens do sertão: um estudo sobre o cinema construindo o imaginário em processo
}

Maria Ignês Carlos Magno*

Doutora em Ciências da Comunicação pela ECA/USP.

Professora do mestrado em Comunicação da Universidade Anhembi Morumbi e da Fundação Escola de Sociologia e Política de São Paulo.

E-mail: unsigster@gmail.com

Resumo: Nesta Videografia, o estudo da construção da identidade do povo brasileiro é o motivo para discutir como o cinema brasileiro contemporâneo representa o imaginário dos seus personagens em trânsito para um novo território, ou o retorno ao lugar de origem. Temática constante nas disciplinas de Sociologia, História, Antropologia, Geografia e Literatura, a seção escolheu filmes em que a estrada e o deslocamento são preponderantes em termos de cenário e ação; e lugar dos fluxos, do fugidio, do efêmero, das sociabilidades, das descobertas e da construção dos imaginários em suas narrativas, como O caminho das nuvens (2003), de Vicente Amorim, e Cinema, aspirinas e urubus (2005), de Marcelo Gomes.

Palavras-chave: identidade, migração, deslocamento, imaginário, cinema.
Abstract: In this Videography, the study of Brazilian identity construction is the reason to discuss how contemporary Brazilian cinema represents the imaginary of its migrant characters, or the ones returning to their birthplaces. Constant issue in sociology, history, anthropology, geography and literature disciplines, the section has chosen films in which the road and the displacement are predominant in terms of scenario and action, and in which they are the place of inflow, evanescence, ephemeral, sociability, discoveries and construction of imaginaries in these films narratives, as in $O$ caminho das Nuvens (2003), by Vicente Amorim, and Cinema, Aspirinas e Urubus (2005) by Marcelo Gomes.

Keywords: identity, migration, displacement, imaginary, cinema.

E me cerro, aqui, mire e veja. Isto não é o de um relatar passagens de sua vida, em toda admiração. Conto o que fui e vi, no levantar do dia. Auroras. Cerro. O senhor vê. Contei tudo. Agora estou aqui, quase barranqueiro. Para

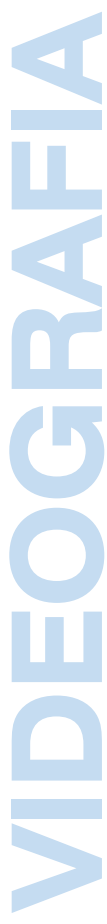

* Com a colaboração de Vicente Gosciola, doutor em Comunicação-Tecnologia da Informação pela Pontifícia Universidade Católica de São Paulo. Mestre em Ciências da Comunicação pela Universidade de São Paulo. Professor permanente do Programa de Pós-Graduação em Comunicação da Universidade Anhembi Morumbi. Autor do livro Roteiro para as novas mídias: do cinema às mídias interativas (2. ed. rev. e ampl. São Paulo: Senac, 2008). 
a velhice vou, com ordem e trabalho. Sei de mim? Cumpro. O Rio de São Francisco - que de tão grande comparece - parece é um pau grosso, em pé, enorme ... Amável o senhor me ouviu, minha ideia confirmou: que o Diabo não existe. Pois não? O senhor é um homem soberano, circunspecto. Amigos somos. Nonada. O diabo não há! É o que eu digo, se for ... Existe é o homem humano. Travessia ${ }^{1}$.

Com a palavra Travessia João Guimarães Rosa encerra, ou melhor, Riobaldo cerra a conversação com um interlocutor em Grande Sertão: Veredas (1956). No romance, Riobaldo não é um retirante, mas um fazendeiro que narra suas aventuras, medos, amores e dúvidas na imensidão daquele sertão. Já Fabiano e sua família, personagens de Graciliano Ramos em Vidas secas (1938), são retirantes do árido, da secura do sertão. Aliás, desde há muito, tanto o sertão de Riobaldo como o de Fabiano e de Sinhá Vitória tem sido tema e cenário constantes na literatura, na telenovela e no cinema brasileiro. Ora contando a vida de retirantes e de flagelados, ora mostrando rememorações de personagens que não vivem mais no sertão, ora mostrando sonhadores em direção à cidade grande ou mesmo em direção ao mais profundo do próprio sertão. Diante de tantas vivências, rememorações e sonhos, o sertão transforma-se em muito mais do que uma imensidão de paisagens áridas; é também travessia, como dizia Riobaldo. Travessia porque o sertão está em toda parte. Porque é parte da existência de Riobaldo, de Fabiano e de todos os sertanejos que lá vivem, que de lá partem, mas que para lá sempre voltam mesmo que em rememorações. Mesmo quando deixam para sempre o sertão. Mesmo quando já não sejam, restam os sertões das memórias. Memórias que as narrativas literárias nos fazem entrar, e que as narrativas do cinema nos fazem ver: seja a labiríntica paisagem do sertão de Riobaldo, seja a seca "planície avermelhada onde os juazeiros alargavam duas manchas verdes" ${ }^{2}$ de Fabiano e sua família, seja tantas outras paisagens e histórias sertanejas contadas nas páginas dos livros ou na tela de cinema. Se as obras literárias são conhecidas porque constituem referências e leituras obrigatórias nas salas de aula, a vasta filmografia existente sobre essa temática é pouco conhecida e menos ainda utilizada como fonte de estudo e de conhecimento do Brasil e do povo brasileiro em constante movimento nesse imenso território e na história.

Justamente porque os filmes do cinema brasileiro permitem a inclusão de temáticas nos programas das disciplinas escolares, e, muitas vezes, devem inclusive ser privilegiados, propomos para esta Videografia o estudo de um dos temas que compõem os conteúdos de várias disciplinas do currículo escolar: o da construção da identidade do povo brasileiro. Como essa temática está presente nas disciplinas de Sociologia, História, Antropologia, Geografia

1. ROSA, João Guimarães. Grande Sertão: Veredas. Rio de Janeiro: José Olímpio Editora, 1956. p. 594

2. RAMOS, Graciliano. Vidas secas. Rio de Janeiro: Editora Record, 1986. p. 9. e Literatura, nossa sugestão é a de discutir como o cinema brasileiro contemporâneo representa o imaginário dos seus personagens em trânsito para um novo território ou o retorno ao território de origem. Para isso, optamos por filmes que têm a estrada e o deslocamento como preponderantes em termos de cenário e ação, como o lugar dos fluxos, do fugidio, do efêmero, das sociabi- 
Nas narrativas que atravessam as paisagens do sertão • Maria Ignês Carlos Magno

lidades, das descobertas, da construção dos imaginários. Dos inúmeros filmes ${ }^{3}$ que apresentam narrativas construídas durante os deslocamentos, escolhemos: O caminho das nuvens (2003), de Vicente Amorim, e Cinema, aspirinas e urubus (2005), de Marcelo Gomes.

\section{O CINEMA CONSTRUINDO O IMAGINÁRIO NAS NARRATIVAS QUE ATRAVESSAM AS PAISAGENS DO SERTÃO}

Histórias sobre migrações e retirantes sempre foram temáticas abordadas pelo cinema brasileiro em diferentes épocas. Os sertões, com suas paisagens áridas, também são cenários constantes nos filmes que retratam a vida de retirantes, de flagelados ou mesmo de sonhadores em direção às cidades grandes. Cidades imaginadas nos sonhos e no desejo de um futuro, mesmo quando esse retirar-se de seu lugar de nascimento signifique deixar para trás as origens, as tradições, os laços e tudo o que pode indicar pertencimentos. Lugares que, nos dias atuais, não são apenas lugares antropológicos, mas condição e suporte de relações globais ${ }^{4}$. Para os que se retiram ou se deslocam, esses lugares se transformam ao longo dos anos em locais da memória, da saudade, da perda ou das transfigurações identitárias. Referências e sentimentos que os filmes aqui trabalhados tornam visíveis nos diálogos das personagens, nas lembranças, nas cartas ou mesmo nas placas das estradas. A questão da migração é importantíssima, mas fundamental é a questão do deslocamento, porque é nele que o migrante, quando vai ao novo território ou volta ao lugar de origem, descreve sua utopia ou antiutopia, imaginando-a individual ou coletivamente.

Nesse universo podemos observar uma filmografia que discute desde a ideia de internacionalização até a de globalização. Vale lembrar as definições de Milton Santos para internacionalização - como o processo de mundializar as relações econômicas, sociais e políticas a partir do início do século XVI - e da globalização - como a nova ordenação político-social a partir do final da Segunda Guerra Mundial ${ }^{5}$. Assim, podemos entender que o campo maior deste estudo são os novos panoramas sociais promovidos pelas alterações econômicas e políticas em períodos demarcados pela "especialização desenfreada dos elementos do espaço - homens, firmas, instituições, meio

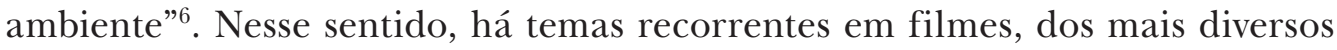
países, que baseiam os conflitos no processo de estabelecimento de novas espacialidades, de comunidades que se constituem por espaços - de vilas a nações -, imaginados por sentimentos comuns. Desse modo, nos filmes em que procuramos conhecer o processo de deslocamento, o transitório é país, é passagem, é o que articula as instâncias de conhecimento e de pertencimento, exatamente por acelerar a capacidade de associação entre informações e experiências e entre as pessoas que estão e que passam. Adiante do cinema de arte, é um cinema fundado em novas espacialidades, em terras imaginadas, em nomadismo ou deslocamentos contínuos, pelo desejo de futuro, de
3. CARLOTA Joaquina. Direção de Carla Camurati. Brasil, 1995 (100 min); TERRA estrangeira. Direção de Walter Salles e Daniela Thomas. Brasil e Portugal, 1996 (100 min); BAILE perfumado. Direção de Paulo Caldas e Lírio Ferreira. Brasil, 1997 (93 min); CENTRAL do Brasil. Direção de Walter Salles. Brasil e França, 1998 (113 min.); NETTO perde sua alma. Direção de Beto Souza e Tabajara Ruas. Brasil, 2001 (102 min); O CAMINHO das nuvens. Direção de Vicente Amorim. Brasil, 2003 (85 min); DEUS é brasileiro. Direção de Carlos Diegues. Brasil, 2003 (110 min); LISBELA e o prisioneiro. Direção de Guel Arraes. Brasil, 2003. (106 min); ÁRIDO Movie. Direção de Lírio Ferreira. Brasil, 2004 (100 min); A MÁQUINA. Direção de João Falcão. Brasil, 2005 (89 min); CINEMA, aspirinas e urubus. Direção de Marcelo Gomes. Brasil, 2005 (101 min).

4. SANTOS, Milton. Da totalidade ao lugar. São Paulo: Edusp, 2005.

5. Id. Metamorfoses do espaço habitado. São Paulo: Hucitec, 1988. p. 5-12.

6. Ibid., p. 13. 
novos traçados de vida, de esperança, exigindo visibilidades mais complexas, densas e paradoxais.

Sendo assim, uma de nossas propostas é a de investigar através do cinema as diferentes formas de representação da realidade social da migração, seus trânsitos pelos territórios e fronteiras. A outra é a de discutir como o cinema brasileiro contemporâneo representa o imaginário dos seus personagens em trânsito para um novo território ou o retorno ao território de origem.

\section{FICHA TÉCNICA}

Titulo original: $O$ caminho das nuvens

Gênero: Drama

Direção: Vicente Amorim

Roteiro: David França Mendes

Música: André Abujamra

Fotografia: Gustavo Hadba

Duração: $100 \mathrm{~min}$

Ano: 2003

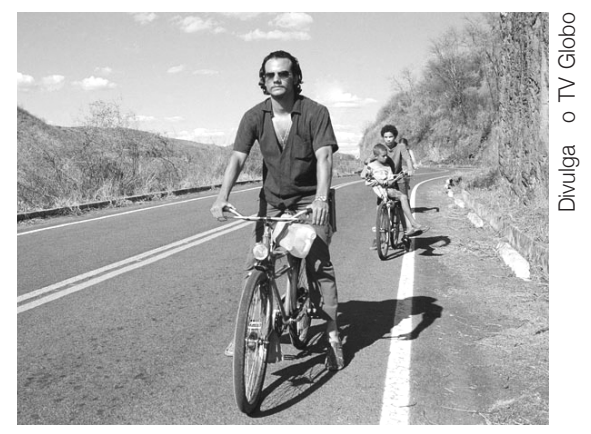

A paisagem é "tudo aquilo que vemos, o que nossa visão alcança", pode "ser definida como o domínio do visível" e não é "formada apenas de volumes,

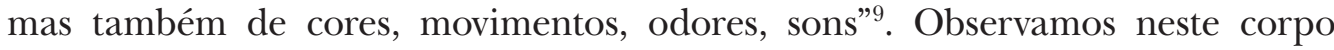
filmográfico estradas que atravessam as paisagens do sertão, as narrativas que apresentam as tramas de uma fina dialética entre homens, territórios e fronteiras. Se os tradicionais estudos de etnologia explicavam que os nômades tinham "sentido de lugar, de território e de tempo, assim como de regresso" ${ }^{10}$, Romão

7. SANTOS, Milton. Da totalidade ao lugar, cit., p. 61.

8. Ibid.

9. Ibid.

10. AUGÉ, Marc. Por una antropologia de la movilidad (Por uma antropologia da mobilidade). 1. ed. Barcelono: Gedisa, 2007. p. 15.

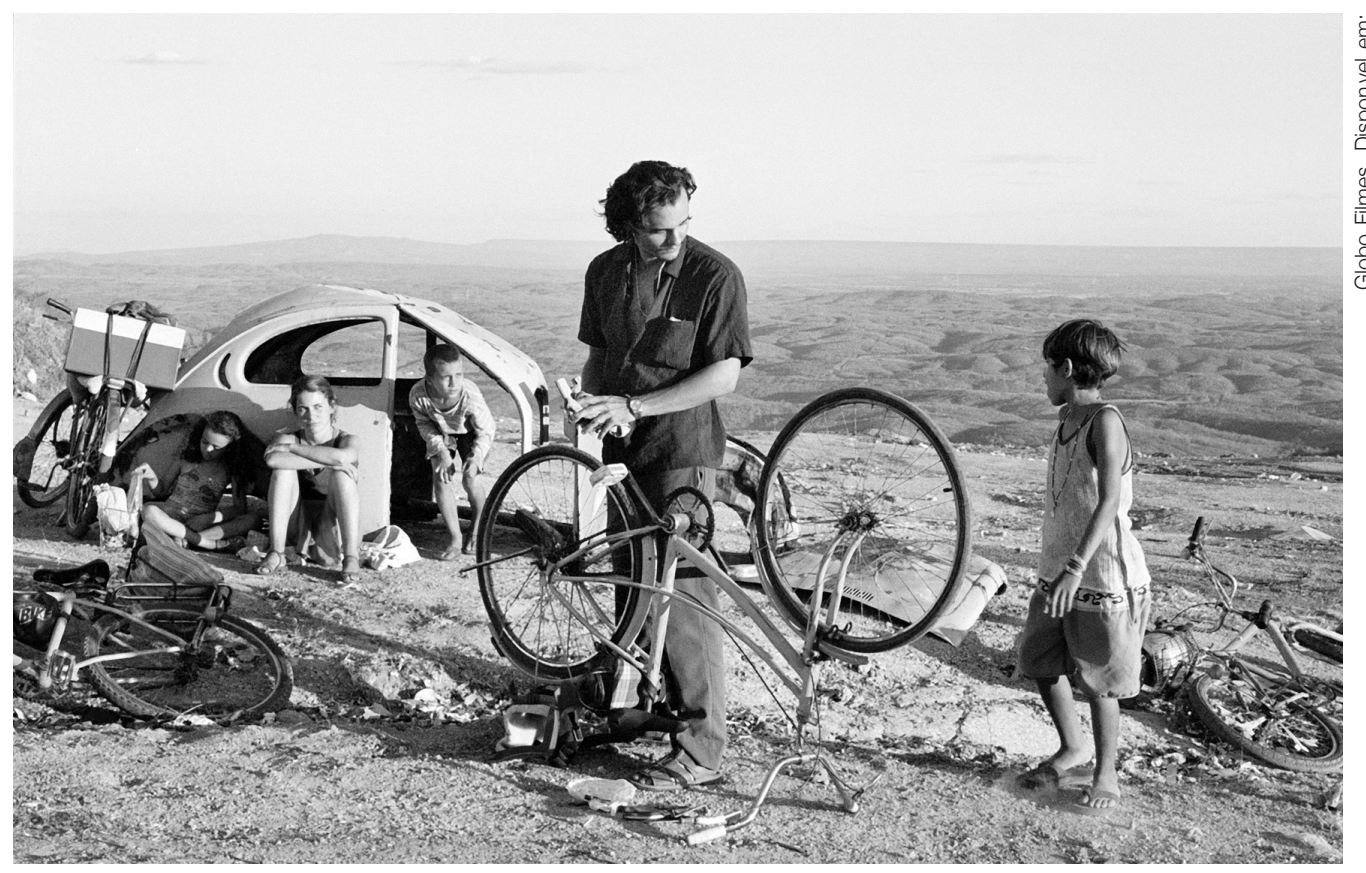


e sua família, personagens do filme $O$ caminho das nuvens, são exemplares para iniciarmos algumas reflexões sobre as complexas relações entre os homens e seus territórios, sejam eles físicos ou imaginados; entre o tradicional conceito de nomadismo e o atual conceito de mobilidade, entre mobilidades e identidade. $\mathrm{O}$ filme $O$ caminho das nuvens conta a história de Romão e seu sonho: o de arrumar um emprego que lhe pague mil reais por mês para que possa sustentar sua família. Para conseguir realizar esse sonho, ele, sua mulher Rose e seus cinco filhos começam uma viagem de bicicleta em direção à cidade do Rio de Janeiro. Antes, porém, precisam passar por Juazeiro para pagar a promessa feita a Padre Cícero. A viagem começa em uma praça chamada Praça do meio do mundo. Essa praça, diferentemente das demais, não ficava no centro de uma cidade ou vila, mas na beira da estrada. Estrada que seria ao mesmo tempo cenário do filme e da vida desses migrantes quase nômades em direção a um sonho. Tudo o que possuíam carregavam em suas bicicletas. Paravam apenas para descansar, dormir, comer, banhar-se nos rios e lagos, que também ficavam nas beiras de estradas. As vezes que entraram em cidades ou vilas não permaneceram por muito tempo. Não se adaptavam, ou melhor, Romão não se adaptava, não conseguia ficar e partiam sempre. A estrada era a casa, o lugar onde aconteciam os conflitos familiares, as descobertas e o reconhecimento do quanto era difícil adolescer em plena estrada, como ocorreu com Antonio, o filho mais velho. A estrada era também o lugar dos encontros efêmeros, das angústias, das sociabilidades transitórias, da alegria sempre embalada por uma música de Roberto Carlos (conhecido compositor e cantor de música popular brasileira), dos afetos e da consciência de que não pertenciam a nenhum lugar. Nas palavras de Rose: "Pertenciam uns aos outros. Não pertenciam ao lugar, mas a eles próprios".

Segundo Marc Augé12, o não lugar não possibilita a constituição de identidades. A mobilidade social, principalmente as migrações populacionais e o imenso fluxo de bens, informação e serviços, é acompanhada da produção de não lugares, espaços efêmeros de ocupação provisória por pessoas em trânsito e, muitas vezes, solitárias. Não lugares são os aeroportos, vias expressas ou autoestradas, salas de espera, centros comerciais, estações de metrô, campos de refugiados, supermercados, espaços ocupados pelos sem-teto etc. ${ }^{13}$. O não lugar é o palco da construção de uma individualidade, justificada pela luta pela sobrevivência, e da perda da identidade local. Todavia, pelo que demonstram os filmes, podemos perceber que o não lugar tem potencial socializador. Cada personagem, em seu deslocamento, ainda que centrado no objetivo de sua busca, desenvolve relacionamentos em seu percurso, o qual, por sua vez, compõe a própria temática das narrativas em desdobramento.

Mas o filme também mostra que a estrada era atravessada por outras estradas que poderiam levar a outros caminhos, a outros destinos. Nessa andança da família, uma das paradas ocorre no estado do Espírito Santo. Nessa permanência, outros aspectos são apresentados, e um deles é o da separação, o talvez nunca mais. O outro é o da condição do migrante nos grandes centros. No Espírito Santo, Romão e Antonio arrumam trabalho como ajudantes de pedreiro. Romão não se adapta e sai do emprego. Antonio fica porque, diferentemente dos irmãos
11. AUGÉ, Marc. Não lugares: introdução a uma antropologia da supermodernidade. São Paulo: Papirus, 1994.

12. Ibid., p. 73-74.

13. SALT, Barry. Film style and technology history and analysis (História e análise do estilo fílmico e tecnologia). London: Starword, 1992. 


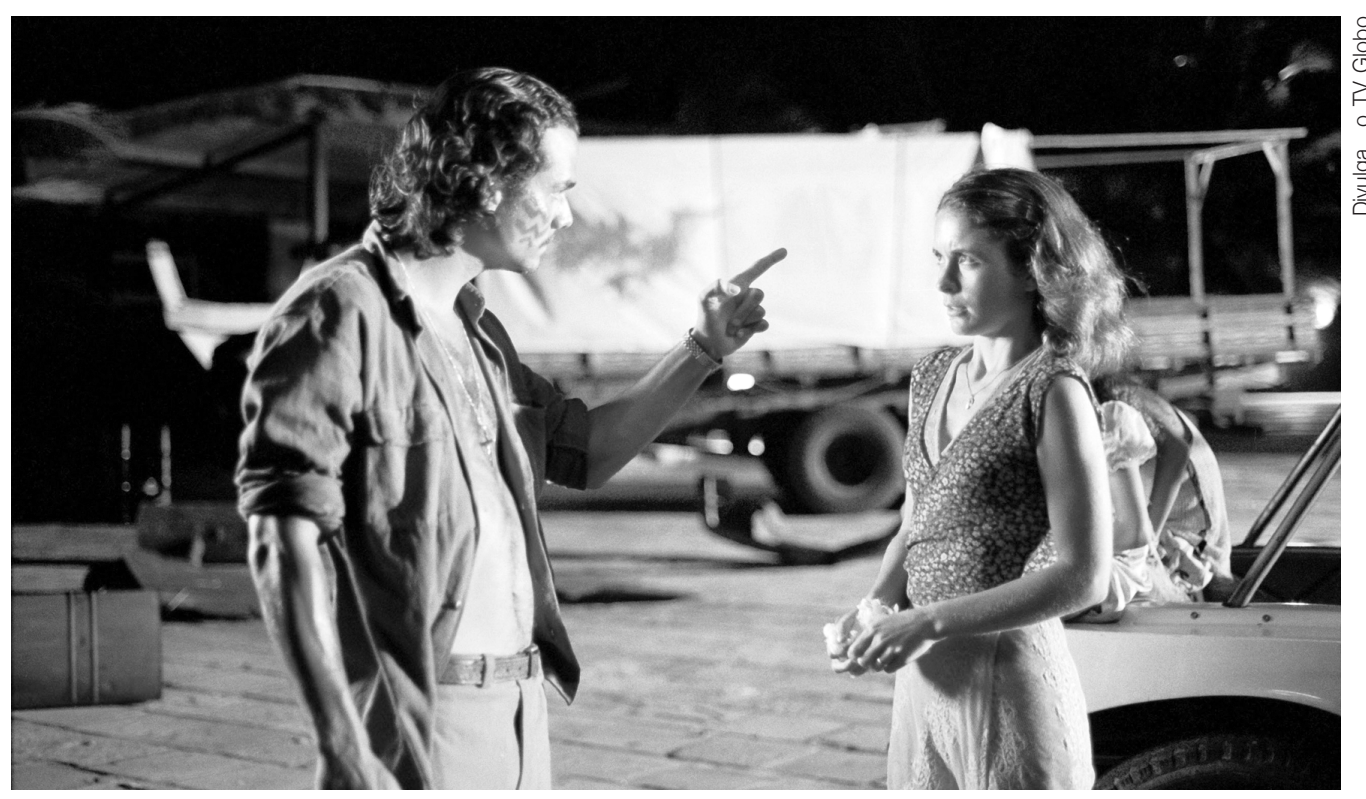

que se deslocam sem entenderem o porquê, ele, mesmo em seus silêncios, questionava aquela andança. $\mathrm{O}$ sonho era de seu pai e não o seu. Antonio queria um lugar, desejava criar raiz, mesmo que para isso fosse necessária a separação da família. Na despedida, a mãe fala: "A gente vai se perder nesse mundo e pode nunca mais se encontrar", outra face na história das migrações. No Rio de Janeiro, após o susto de Rose ao perceber que vai morar em um lugar exatamente igual ao de onde saiu - uma favela -, a família vai até o Cristo Redentor, lugar turístico e não de romarias, como a de Juazeiro. Enquanto observam e admiram a paisagem de um mar sem fim, Romão olha para a imensidão e ensaia um querer continuar a sua caminhada. Rose impede o desejo nômade de seu marido. Na volta para casa, a televisão apresenta o show de Roberto Carlos. Parados em frente da TV, ouvem a música que sempre cantavam quando estavam na estrada. Antonio também assiste ao mesmo programa. Separados, o veículo que permite a lembrança e a continuidade dos laços é a televisão: tele-ver ou o ver de longe. Nesse não lugar que existe, ocorre a possibilidade do reencontro. Através da tela de TV, os laços foram restituídos na memória.

\section{FICHA TÉCNICA}

Titulo original: Cinema, aspirinas e urubus Gênero: Drama

Direção: Marcelo Gomes

Roteiro: Marcelo Gomes, Paulo Caldas e Karim Aïnouz

Música: Tomás Alves de Souza

Fotografia: Mauro Pinheiro

Duração: $90 \mathrm{~min}$

Ano: 2005

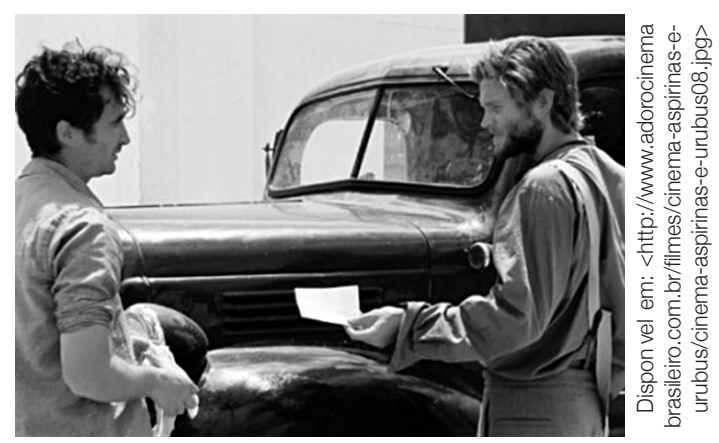


Um lugar é onde tudo começa, onde todas as viagens se iniciam. As estradas que atravessam regiões e territórios, colocando personagens reais e ficcionais em contato, produzem histórias singulares como de Ranulpho e Johann, no filme Cinema, aspirinas e urubus. O ano é 1942; o local, o meio do sertão nordestino. As personagens, Johann, alemão fugido da Segunda Guerra Mundial, vende aspirinas pelo interior do país, e Ranulpho, um homem simples que sempre viveu no sertão e quer ir embora para o Rio de Janeiro. Após ganhar uma carona de Johann, passa a trabalhar para ele como ajudante. Viajando de caminhão de povoado em povoado, a dupla exibe filmes promocionais sobre o remédio milagroso para pessoas que jamais tiveram a oportunidade de ir ao cinema. Aos poucos surge entre eles uma forte amizade e a história de cada um vai se revelando nas conversações travadas durante as viagens.

Ranulpho era de um povoado chamado Bonanza, que descreve como um lugar com cinco casas e uma cruz no centro. Já havia deixado aquele lugar antes, mas voltou quando a fome bateu forte. Agora estava indo para Triunfo e de lá para a cidade do Rio de Janeiro, tentar a vida. Ia para o lugar de onde Johann partira em seu caminhão em direção ao interior do Brasil. Para Ranulpho, Johann era "um alemão autêntico vindo do outro lado do mundo para trazer o futuro".

Trazer o futuro para "um povo atrasado", para um país tão "atrasado que nem a guerra chegava por aqui”. Ranulpho saiu de sua terra por não suportar aquela vida, a vida do sertanejo e a secura da região. Saiu porque não gostava de nada daquilo e queria viver em uma cidade grande. Entretanto,

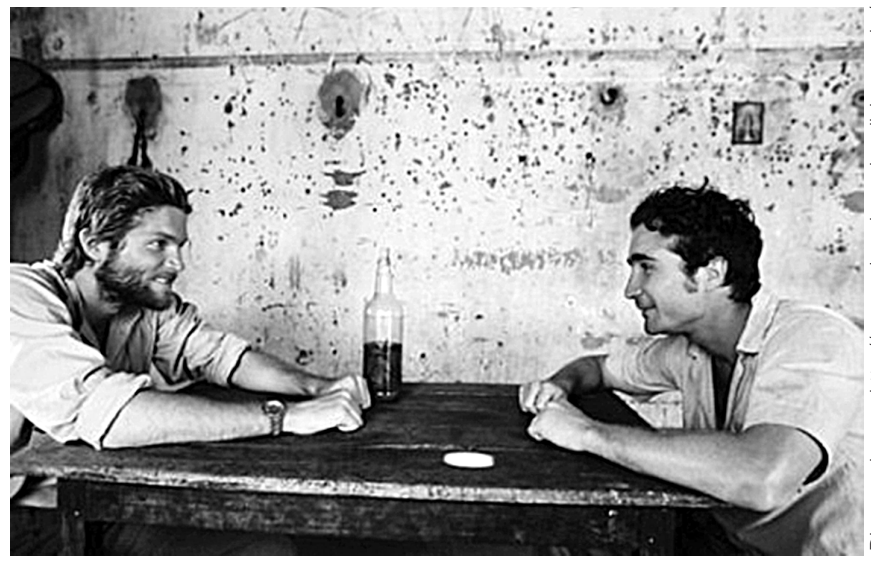
registrou em um diário as viagens, os povoados, o agreste, a amizade, as personagens que conheceu e as histórias próprias de cada lugar por onde passou até chegar à cidade do Rio de Janeiro. Ranulpho mudou apenas a maneira de imprimir os lugares e as histórias que já estavam gravados na gramática de seu ser.

Johann saíra da Alemanha porque não suportava a guerra. Fugira de uma situação com a qual não concordava. Nas conversas com Ranulpho, que negava a situação do país e o atraso do povo, dizia que a viagem pelo interior do Brasil era a "melhor parte porque não caía bombas do céu". Como Ranulpho, desejava tentar a vida em outro lugar. Queria apenas viver em paz. Ao contrário de Ranulpho, que não levava nada que lembrasse o lugar de onde saíra, Johann trouxera consigo documentos de identidade e fotografias. Imagens de casa, imagens de seu lugar de origem, que se revelam significativas em dois momentos da viagem: quando é picado por uma cobra e no momento em que o Brasil entra na Guerra, e os alemães são declarados inimigos do Brasil e do povo brasileiro. 
Ao ser picado, Johann, após receber remédio caseiro e regional, no delírio da febre sonha e fala em alemão. Ranulpho, ao lado do amigo, inicia uma conversação consigo mesmo. Fala de sua origem sertaneja e da imagem que todos na capital têm do nordestino, "como se todos fossem iguais". Em tom de monólogo, já que Johann não está escutando, Ranulpho, contrariamente ao discurso anterior de que esta terra "é uma terra sem saudade", confessa que a primeira coisa que fará quando chegar à cidade, "no dia seguinte", será "escrever uma carta para a mãe".

O outro momento é o da entrada do Brasil na Guerra. Os dois amigos ouvem pelo rádio que a partir daquela data: 18 de agosto de 1942, todos os alemães foram considerados inimigos do Brasil. Em silêncio, os dois olham para a interminável paisagem do agreste. Como poderiam ser inimigos? Depois do silêncio, Johann se lembra de quando ouviu no rádio que estavam recrutando pessoas para trabalhar na extração da borracha no Amazonas e decide ir para lá. Decisão que exigia que se desfizesse de tudo que pudesse identificá-lo com o alemão. Com a ajuda de Ranulpho, Johann queima todos os seus documentos e fotografias, e parte no trem que levava os flagelados da seca e da miséria para o interior do Amazonas. Lá, Johann precisaria ser outro, reinventar-se como pessoa e construir uma nova identidade. Ranulpho, que ganhara as chaves do caminhão do alemão, parte em direção ao Rio de Janeiro, onde, embora brasileiro do sertão, também não seria mais o mesmo. Como Johann, a cidade-lugar imaginado e, depois real, exigiria que ele também, de alguma maneira, viesse a ser outro. Bonanza, Triunfo e todas as paisagens que lhes eram familiares transformar-se-iam aos poucos em lugares da memória e da saudade que teriam nas cartas uma forma de lembrar e de não esquecer.

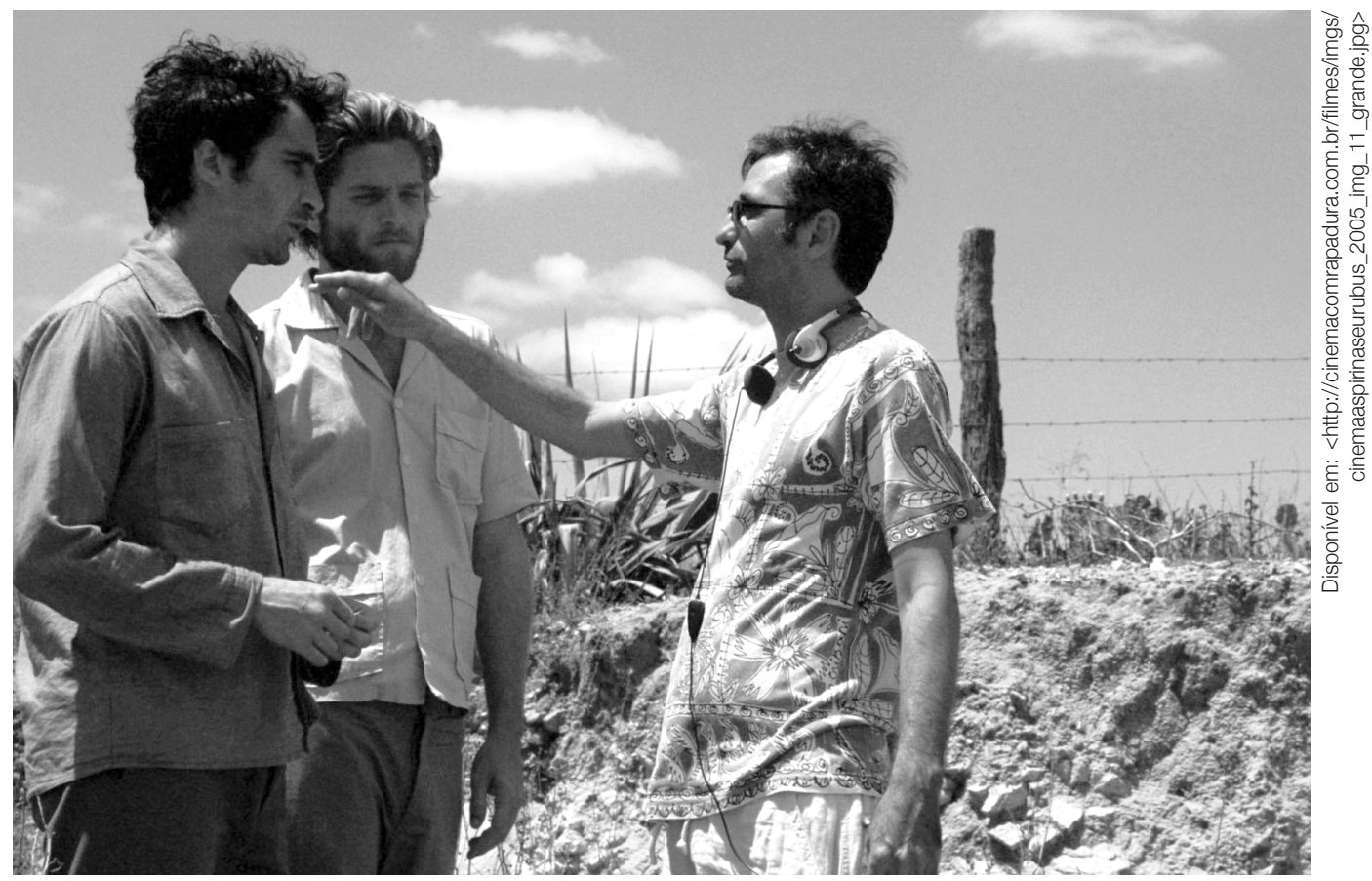




\section{OUTRAS LEITURAS, OUTROS EXERCÍCIOS}

\section{A materialidade de um filme}

Se a história, a literatura, a geografia, as questões sociais e culturais se apresentam na fotografia, na música e no cinema - facilitando o ensino e o estudo e se aproximando à vivência dos alunos -, um filme pode ser objeto de estudo em seus aspectos materiais, em sua tecnologia e estilo filmico, como se dá na teoria desenvolvida por Barry Salt ${ }^{14}$. Entendamos a tecnologia como o conjunto de todos os instrumentos físicos de registro e edição de imagem e som, que por si só potencializam a expressão fílmica. E entendamos o estilo como o conjunto de procedimentos específicos do cinema, como a composição da imagem (a disposição dos objetos dentro do quadro), a escala do plano (se do personagem aparece só o seu rosto em um close-up, ou o seu corpo inteiro num plano geral), a angulação e o movimento de câmera, a iluminação, a edição, a direção etc. $\mathrm{O}$ modo de configuração do estilo e da tecnologia aplicado a um plano e a todo o filme é o que organiza tudo aquilo a que o espectador assistirá durante a projeção ${ }^{15}$.

Por exemplo, em $O$ caminho das nuvens o deslocamento é orientado pelo sonho de Romão: viajar de bicicleta em direção ao Rio de Janeiro, arrumar um emprego que lhe pague mil reais, sustentar a mulher Rose e os cinco filhos. As relações e o destino de todos já estão definidos antes do início da história, razão pela qual todos permanecem em deslocamento por toda a duração do filme. A materialização do deslocamento pelos planos não se dá nas vilas ou cidades, mas nas estradas, através de planos em que os personagens, durante o trajeto, descrevem seus ideais e esperanças. Há pontuações narrativas demarcadas pelas separações dos integrantes da família, que segue se deslocando entre atividades que revelam os sentimentos comuns, integrando-a e sociabilizando-a. A média de duração de plano (MDP) de todo o filme é de 5,37 segundos por plano, uma média muito pequena para a filmografia brasileira. $\mathrm{O}$ fato de o filme ter uma edição muito ágil pode ser consequência da necessidade de manter a narrativa bastante descritiva quanto aos relacionamentos entre os familiares; mas, ao mesmo tempo, para demonstrar plenamente a sua evolução entre as tantas estradas percorridas pelos protagonistas. O tempo do filme em que a família de Romão se desloca é de 69 minutos e 15 segundos, o que corresponde a mais de $89 \%$ de toda a sua duração. Os deslocamentos são da esquerda para a direita, do sertão para o mar, mas, nos últimos planos do filme, a família que chegou ao Rio de Janeiro resolve voltar ao interior, só que agora pretende seguir para Brasília, quando a câmera alça voo, da direita para a esquerda.

Cinema, aspirinas e urubus organiza o espaço, o tempo e o trajeto de Johann e Ranulpho, que seguem a mesma direção, mas em sentidos opostos. A materialização da deslocografia é obtida pelos planos que não constroem vilas ou cidades, mas estradas, onde os personagens tentam esquecer suas vidas anteriores. As pontuações narrativas são desenvolvidas por falas muito específicas em cada novo deslocamento. O tempo de filme que descreve o deslocamento dos

14. Ibid., p. 24-25; BORDWELL, David. Narration in the fiction film (A narração do filme de ficção). London: Routledge, 1986. p. 49-51; XAVIER, Ismail. O discurso cinematográfico. Rio de Janeiro: Paz e Terra, 2005. p. 192.

15. Ou Average shot length-ASL, de acordo com Barry Salt, seu criador, também chamado por ele de cutting rate, aqui considerada como a Média de Duração do Plano (MDP), que é calculada através da divisão da duração do filme pelo número de planos: SALT, Barry. Film style..., cit., p. 146. 
comunicação \& educação • Ano XV • Número 1 • jan/abr 2010

personagens é o maior entre os filmes aqui estudados: 86 minutos, ou $91 \%$. Entretanto, a MDP é de 18,88 segundos por plano, a média mais alta entre os nove filmes aqui investigados. Não há, todavia, discrepância entre o tempo de deslocamento no filme e a MDP; ao contrário, justifica-se plenamente manter os protagonistas em deslocamento contínuo, sensação exatamente corroborada pelos longos planos que elevaram a MDP a tal patamar. O deslocamento é do sertão para o mar, seguindo o desejo de Ranulpho, quando passa a conduzir solitário o caminhão que ganhou de Johann.

\section{No filme. O cinema, o rádio e a história}

Cinema, aspirinas e urubus não teve o texto literário como inspiração. Saiu das anotações do Diário de Viagem do personagem Ranulpho. O filme tem no relato (realidade-ficção) ou nesse Diário o ponto de partida para sua narrativa.

Pelo rádio os dois amigos tomam conhecimento da entrada do Brasil na Guerra, bem como de outro estado brasileiro, a Amazônia, e de outra parte pouquíssima estudada de nossa história: a da extração da borracha e a forma como as pessoas eram recrutadas para trabalhar naquela atividade econômica, o que vai repetir-se na década de 1970. Outra paisagem, outra atividade, uma mesma realidade: a migração, a fuga do agreste, do flagelo das secas em diversas direções de um mesmo país. Oportunidade interessante para se estudar a participação do Brasil na Segunda Guerra Mundial e a situação dos alemães, italianos e japoneses, imigrantes que viviam no Brasil e que haviam chegado desses países, considerados, a partir daquela data, inimigos dos brasileiros.

Consideramos inevitáveis os estudos sobre os dois meios de comunicação que, juntamente com Ranulpho e Johann, são personagens fundamentais no filme e na história: o rádio e o cinema. $\mathrm{O}$ caminhão de Johann levava o cinema para vender aspirinas a uma população que nunca tinha visto imagens em movimento, mas conhecia o rádio. $\mathrm{O}$ rádio era o meio que colocava todos em sintonia com o mundo, com os acontecimentos, com o entretenimento, no caso, a música, os programas musicais. Se pelo noticiário do rádio podemos recuperar uma parte da história do mundo, ou seja, a Segunda Guerra, podemos também reaver uma parte de nossa história: o período do Estado Novo (1937-1945), e da ditadura de Vargas, e o significado que o rádio desempenhou nesse momento da história mundial, em geral, e de nossa história, em particular. O rádio era o meio de comunicação pelo qual Getúlio fazia os pronunciamentos e a propaganda de seu governo e de seus feitos. Pelo rádio, pela voz, a figura do chefe se materializava no momento em que abria seu programa diário com a pergunta: "Você sabe com quem está falando?”. Como a imagem estava só nos noticiários do cinema, realidade distante daquela população, a voz era o elemento que colocava o povo em sintonia direta com o comandante; a voz era o instrumento que permitia que chefe e povo se tornassem um só corpo, uma só nação.

Mas essa não é a única parte da história que o rádio, personagem do filme, possibilita: também remete ao estudo da trilha sonora. Se atentarmos 
para as letras das músicas, duas possibilidades de análise se abrem: a primeira é a do estudo das paisagens e dos climas do Brasil. Seus contrastes. Enquanto o caminhão corta o interior do sertão, do agreste, do árido, as letras falam das belezas da terra brasileira, da abundância, das maravilhas da terra ou de uma parte do país. A segunda é um recurso que o filme usa para trabalhar a contradição existente entre o discurso e a realidade, marca da mídia, no caso materializada no personagem Ranulpho. Durante toda a trajetória de sua viagem, ele nega sua terra, suas origens, a saudade. Sobre a fala que nega, sobrepõe-se a letra de música que exprime o sentimento e a saudade que a saída de seu lugar de origem provoca no retirante.

Outro dado interessante, que pode ser ampliado e servir como ponte para estudar outros fatos da história política do Brasil ou do mundo, é o que se refere à história desses caminhões que levavam o cinema para o interior. No caso do Brasil e do filme, Johann levava o filme de propaganda de remédios; na Espanha, durante a Guerra Civil Espanhola (1936), os caminhões também levavam o cinema e os ideais revolucionários para regiões distantes dos centros dos acontecimentos políticos. Aliás, esse é outro tema que pode ser largamente explorado em sala de aula.

Assim, os meios de comunicação, suas diferentes funções, apropriações e usos, constituem produção social de sentido: são partes integrantes da vida, da cultura, do cotidiano das pessoas em diferentes épocas, carregado de significados, transformados, que deram origem e se modificaram até chegar à atualidade. Nesse sentido merecem, eles próprios, um estudo aprofundado.

\section{REFERÊNCIAS BIBLIOGRÁFICAS}

AUGÉ, Marc. Por una antropologia de la movilidad (Por uma antropologia da mobilidade). 1. ed. Barcelona: Gedisa, 2007.

Não lugares: introdução a uma antropologia da supermodernidade. São Paulo: Papirus, 1994.

BORDWELL, David. Narration in the fiction film (A narração do filme de ficção). London: Routledge, 1986.

RAMOS, Graciliano. Vidas secas. Rio de Janeiro. Editora Record, 1986.

ROSA, João Guimarães. Grande Sertão: Veredas. Rio de Janeiro: José Olímpio Editora, 1956.

SALT, Barry. Film style and technology history and analysis (História e análise do estilo fílmico e tecnologia). London: Starword, 1992.

SANTOS, Milton. Da totalidade ao lugar. São Paulo: Edusp, 2005.

Metamorfoses do espaço habitado. Hucitec: São Paulo, 1988.

XAVIER, Ismail. O discurso cinematográfico. Rio de Janeiro: Paz e Terra, 2005. 
comunicação \& educação • Ano XV • Número 1 • jan/abr 2010

\section{Filmografias}

A MÁQUINA. Direção de João Falcão. Brasil, 2005 (89 min).

ÁRIDO Movie. Direção de Lírio Ferreira. Brasil, 2004 (100 min).

BAILE perfumado. Direção de Paulo Caldas e Lírio Ferreira. Brasil, 1997 (93 $\min )$.

CARLOTA Joaquina. Direção de Carla Camurati. Brasil, 1995 (100 min).

CENTRAL do Brasil. Direção de Walter Salles. Brasil e França, 1998 (113 min).

CINEMA, aspirinas e urubus. Direção de Marcelo Gomes. Brasil, 2005 (101 min).

DEUS é brasileiro. Direção de Carlos Diegues. Brasil, 2003 (110 min).

LISBELA e o prisioneiro. Direção de Guel Arraes. Brasil, 2003 (106 min).

NETTO perde sua alma. Direção de Beto Souza e Tabajara Ruas. Brasil, 2001 (102 $\min )$.

O CAMINHO das nuvens. Direção de Vicente Amorim. Brasil, 2003 (85 min).

TERRA estrangeira. Direção de Walter Salles e Daniela Thomas. Brasil e Portugal, 1996 (100 min). 